
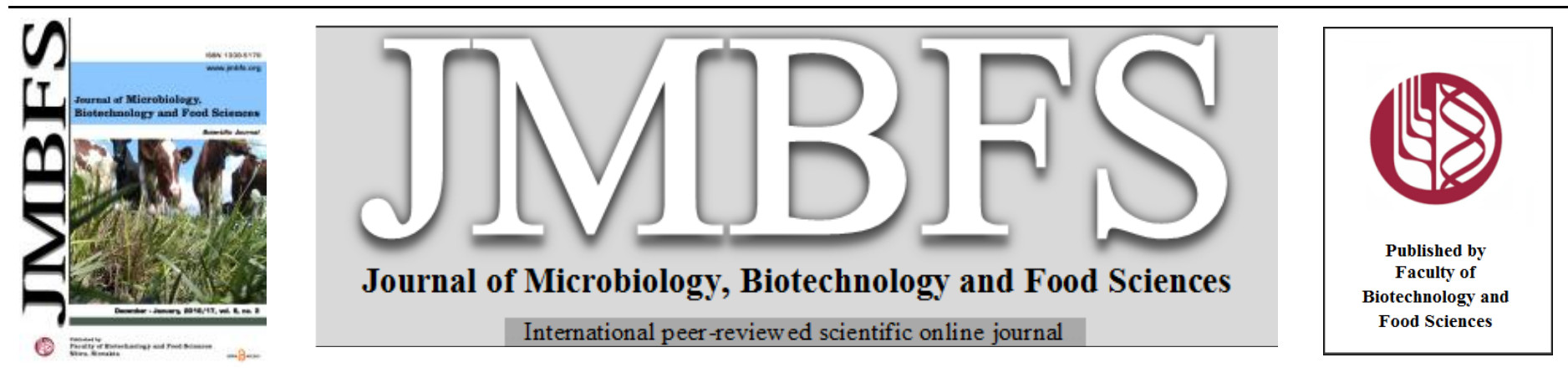

\title{
COMPARISON OF HYALURONIC ACID BIOSYNTHESIS BY THE RECOMBINANT Escherichia Coli STRAINS IN DIFFERENT MODE OF BIOREACTOR OPERATION
}

\author{
Zee-Wei Lai ${ }^{{ }^{*}}$, Raha Abdul Rahim ${ }^{2}$, Arbakariya B. Ariff ${ }^{2,3}$ and Rosfarizan Mohamad ${ }^{2,3}$

\section{Address(es):} \\ ${ }^{1}$ Taylor's University Lakeside Campus, Jalan Taylor's 47500 Subang Jaya, Selangor Darul Ehsan, Malaysia. \\ ${ }^{2}$ Faculty of Biotechnology and Biomolecular Sciences, Universiti Putra Malaysia, 43400 UPM Serdang, Selangor Darul Ehsan, Malaysia. \\ ${ }^{3}$ Biomanufacturing and Bioprocessing research Center, Universiti Putra Malaysia, 43400 UPM Serdang, Selangor Darul Ehsan, Malaysia.
}

*Corresponding author: zeewei.lai@ taylors.edu.my

doi: 10.15414/jmbfs.2016/17.6.3.905-910

ARTICLE INFO

Received 15. 6. 2016

Revised 8. 8. 2016

Accepted 4. 10. 2016

Published 1. 12. 2016

Regular article

open $\bigodot_{\text {ACCESS }}$

\begin{abstract}
Recombinant $E$. coli was used as a host to explore the biosynthesis of Hyaluronic acid (HA) in Gram-negative strain using the optimized medium. In addition, measurement of HA molecular weight produced by the recombinant strains in shake-flask and $2 \mathrm{~L}$ stirred tank bioreactor (batch and fed-batch cultivation) were compared too. In this study, the hasA and hasE genes expressed together in a plasmid in recombinant $E$. coli strains were successfully produced HA using glucose as a carbon source under aerobic condition. Production of $127 \mathrm{mg} / \mathrm{L} \mathrm{HA}$ was observed in a batch fermentation process with the highest HA molecular weight (70056 Da) using strain sAE in $2 \mathrm{~L}$ stirred tank bioreactor with controlled DO at 30\%. The fed-batch culture with constant feeding of glucose was favorable for cell growth and the highest $\mathrm{OD}_{600}$ achieved at 1.923. However, the HA biosynthesis and molecular weight in fed-batch culture were lower than that observed in the batch culture.
\end{abstract}

Keywords: Recombinant, Hyaluronic acid, Batch cultivation, Fed -batch cultivation

\section{INTRODUCTION}

HA can be used in various fields such as cosmetics, nutraceutical and osteoarthritis due to its biological and physiological properties (Kogan et al., 2007). The worldwide market value is estimated to be over US \$ 1 billion (Liu $\boldsymbol{e t}$ al., 2011). In past researches, a vast number of scientists argued that Streptococci spp. can be fairly difficult or expensive to mass cultivate and it was also found to be a challenge to genetically manipulate the strains. It was shown to have the potential to produce exotoxins, which is unsuitable for producing HA applied for medical applications (Kogan et al., 2007; Shih et al., 2013). All these drawbacks may have played a part in encouraging researchers to favor the incorporation of novel biotechnological productive methods. This was to solve the pathogenic problems as well as to avoid any contaminations that may have a negative effect towards health. Thus, in the recent years, HA biosynthesis in recombinant microorganisms through metabolic engineering emerged as an attractive alternative method that could reduce safety concerns associated with the use of pathogenic microorganisms and avian products.

Appropriate process conditions are crucial for the metabolic engineered strains to reach their maximum potential, as they may allow the modified metabolic routes to behave as predicted. The first metabolic engineering study effort for recombinant biosynthesis of HA was reported by Frohberg and Koch (2004) who expressed the HA synthase genes of human and Chlorella virus in algal plant. There have been a few approaches for the production of HA using metabolically engineered microorganisms. Both Gram-positive and Gram negative bacteria were used as hosts in producing the HA (Liu et al., 2011). These include Bacillus sp. (Widner et al., 2005; Chien and Lee, 2007a), Lactococcus lactis (Chien and Lee, 2007b; Prasad et al., 2010); for Gramnegative bacteria were Escherichia coli (Yu and Stephanopoulos, 2008; Rehm 2009), and Agrobacterium sp. (Mao and Chen, 2007). For instance, Gram positive Bacillus subtilis was used as expression host, due to its ability to secrete similar cell-wall composition features with Streptococcus (Widner et al., 2005). Yu and Stephanopoulos (2008) incorporated the use of recombinant E. coli under fed-batch fermentation using Luria broth as the fermentation medium and resulted in a HA concentration of $0.19 \mathrm{~g} / \mathrm{L}$. Another study using E. coli under batch fermentation using also Luria broth as the fermentation medium was able to produce a HA concentration of $0.325 \mathrm{~g} / \mathrm{L}$ (Jongsareejit $\boldsymbol{e t}$ al., 2007). The HA concentration produced by the recombinant $B$. subtilis indicates that the genetic engineering approach provides new opportunities for capsular polysaccharides to be produced in a heterologous host.

Uridine diphosphate (UDP)-glucose (UDP-GlcA) and UDP-GlcNAc are two nucleotide sugar substrates required for HA synthesis and are produced as precursors of bacterial cell wall components. In addition to that, there is stiff competition for metabolites between HA synthesis and cellular growth due to glucose-6-phosphate and fructose-6-phosphate being consumed in the pentose phosphate pathway and glycolysis respectively (Mao et al., 2009). It has been elucidated that HA is synthesized in various cells by polymerization of the monosaccharides from two nucleotide sugar (UDP)-glucuronic acid (UDPGlcUA) and UDP-N-GlcNAc via HA synthase into a long chain (DeAngelis et al., 1993). As mentioned earlier, UDP-GlcNAc is commonly present in most bacteria as precursors of cell wall components. In contrast, UDP-GlcUA is not commonly used for building their cell wall (Chien and Lee, 2007a). Therefore, HA synthase is the only enzyme that lacking in most bacteria important for HA biosynthesis.

In this study, recombinant $E$. coli was used as a host to explore the biosynthesis of $\mathrm{HA}$ in Gram-negative strain using the optimized medium. In addition, measurement of HA molecular weight produced by the recombinant strains in shake-flask and $2 \mathrm{~L}$ stirred tank bioreactor (batch and fed-batch cultivation) were compared.

\section{MATERIALS AND METHODS}

\section{Microorganism and Medium}

Recombinant E. coli Rosetta (DE3) (CalbioChem, Germany) was used as an expression host of the pRSF and duet PCDF plasmids. The gene sets included two genes set hasA and hasE genes (strain sAE) in one plasmid and hasA and $h a s E$ in one plasmid with addition of hasE gene in separate plasmid (strain sAEE). The cells were grown at $37^{\circ} \mathrm{C}$ with $200 \mathrm{rev} / \mathrm{min}$ shaking speed for $12 \mathrm{~h}$ either in Luria-Bertani (LB) plates or in the LB liquid medium (as an inoculum) supplemented with kanamycin (CalbioChem, Germany) (50 $\mu \mathrm{g} / \mathrm{mL})$ and chloramphenicol (BioWorld, USA) $(35 \mu \mathrm{g} / \mathrm{mL})$ for sAE strains, additional 50 $\mu \mathrm{g} / \mathrm{mL}$ of streptomycin (CalbioChem, Germany) for sAE-E strains. The fermentation medium contained (in $\mathrm{g} / \mathrm{L}$ ) glucose 50 , tryptone 15 , yeast extract 5 , $\mathrm{KH}_{2} \mathrm{PO}_{4} 2, \mathrm{~K}_{2} \mathrm{HPO}_{4} 2, \mathrm{MgSO}_{4} .7 \mathrm{H}_{2} \mathrm{O} 0.5$. The culture medium was sterilized at $121^{\circ} \mathrm{C}$ for $15 \mathrm{~min}$. The glucose and $\mathrm{MgSO}_{4} \cdot 7 \mathrm{H}_{2} \mathrm{O}$ were autoclaved separately. 
The kanamycin, chloramphenicol and streptomycin were sterilized by filtration using $0.45 \mu \mathrm{m}$ nylon syringe membrane filter (ThermoScientific, USA) Fermentations were carried out in duplicates and the mean value of each experiment was obtained.

\section{Fermentation in Shake-flask}

To investigate the effect of incubation temperature $\left(30^{\circ} \mathrm{C}, 37^{\circ} \mathrm{C}\right.$ and temperatureshift, $37^{\circ} \mathrm{C}-30^{\circ} \mathrm{C}$ ) for HA biosynthesis by the recombinant strains (sAE and sAEE), experiments were carried out using a $250 \mathrm{~mL}$ Erlenmeyer flask. The flask cultures were incubated in rotary shaker at $200 \mathrm{rev} / \mathrm{min}$ with different temperatures. To initiate the fermentation, 1 loop of colony culture was transferred to $50 \mathrm{~mL}$ of $\mathrm{LB}$ inoculum medium for 12 hours at $\mathrm{pH} 7$, and $10 \%$ $(\mathrm{v} / \mathrm{v})$ of inoculum was inoculated into the $250 \mathrm{~mL}$ shake flask containing $50 \mathrm{~mL}$ of the production medium and run for another 12 hours at initial $\mathrm{pH} 7$ with different temperatures. For temperature shift, temperature was shifted to $30^{\circ} \mathrm{C}$ once inducer is added. Inducer of $0.5 \mathrm{mM}$ isopropyl $\beta$-D-1-thiogalactopyranoside (IPTG) was added to induce the expression of has $A$ genes when $\mathrm{OD}_{600}$ reached about 0.6 .

Two different induction times (when cell growth $\mathrm{OD}_{600}=0.6 ; \mathrm{OD}_{600}=1.0$ ) were investigated by using $0.5 \mathrm{mM}$ of IPTG. Four different IPTG concentrations ( 0 $0.1,0.5$, and $1.0 \mathrm{mM}$ ) were investigated when the cell growth reached the middle exponential phase. All experiments are run at $37^{\circ} \mathrm{C}, 200 \mathrm{rev} / \mathrm{min}$ and with initial $\mathrm{pH} 7$.

\section{Fermentation in 2 L Stirred Tank Bioreactor}

\section{Batch Fermentation}

All experiments were conducted using a $2 \mathrm{~L}$ stirred-tank bioreactor using strain $\mathrm{sAE}$ and sAE-E. The dissolved oxygen of batch HA fermentation was controlled according to requirement of the experiments $(20 \%, 30 \%$ and $50 \%)$. Dissolved oxygen was provided by sparging filtered air at a flow rate of $1 \mathrm{vvm}$ and was maintained according to requirement by automatically adjusting the agitation rate from 50 to $350 \mathrm{rev} / \mathrm{min}$ with half-pitched double blade helical ribbon impeller, via sequential cascade control.

\section{Fed-batch Fermentation}

Fed-batch fermentations were carried out in a $2 \mathrm{~L}$ stirred-tank bioreactor equipped with half-pitched double blade helical ribbon impeller. The working volume was $1 \mathrm{~L}$ with initial batch culture working volume $500 \mathrm{~mL}$. The fed-batch feed protocol was designed as initially the cells were cultivated in $4 \mathrm{~h}$ of batch phase, to stabilise the cells and control the lag phase behaviour. The cultivation was the batch phase followed by a constant glucose feed before glucose was depleted. Initial glucose $(10 \mathrm{~g} / \mathrm{L})$ was added to create batch phase before the constant feed phase was started. The feed solution $(10 \mathrm{~g} / \mathrm{L}$ glucose and other components of medium) were pumped into the bioreactor at a feeding rate of 2 $\mathrm{ml} / \mathrm{min}$ by a peristaltic pump (Watson Marlow $101 \mathrm{U} / \mathrm{R}$, England). The fermentation was carried out for $12 \mathrm{~h}$, with temperature maintained at $37^{\circ} \mathrm{C}$ and $\mathrm{pH}$ controlled at 7.0 by the automatic addition of $3 \mathrm{M} \mathrm{NaOH}$ and $3 \mathrm{M} \mathrm{HCl}$. A polarographic oxygen electrode was used to determine the dissolved oxygen level (DOT). The dissolved oxygen never dropped below 30\% air saturation. Also, 1 $\mathrm{mM}$ of IPTG was added to express hasA gene in E. coli.

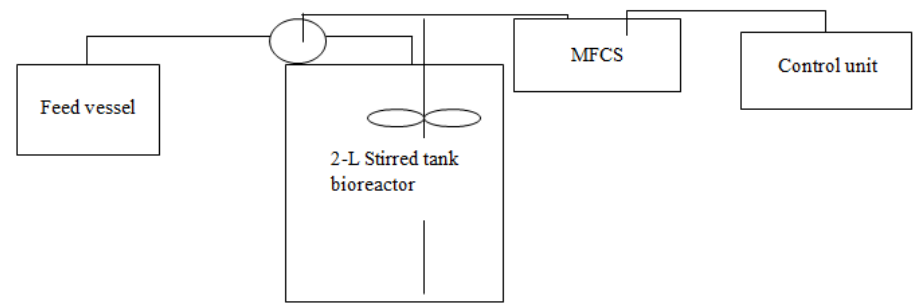

Figure 1 Schematic diagram for fed-batch fermentation set-up

The bioreactor was connected to the multifermenter control system (MFCS) for controlling the feeding rate of the substrate and also controls some of the bioreactor operating variables. Control of the peristaltic pump was facilitated using MFCS/win software, which is a fermenter supervisory control and data acquisition system (SCADA) for simultaneous control of multiple fermenters.

\section{Analytical Methods}

All samples were withdrawn at regular time intervals for analysis of cell, HA and glucose concentration. Cell growth was observed by measuring the optica density of the culture broth at $600 \mathrm{~nm}$ using a spectrophotometer. Correlation between the dry cell weight (DCW) and OD was estimated from several batch experiments using the equation: $\mathrm{DCW}(\mathrm{g} / \mathrm{L})=1.489 \times \mathrm{OD}$
The supernatants were used for HA and glucose determination. After the removal of the cell pellet for cell growth determination, two volumes of ethanol were added to one volume of the supernatant in a $15 \mathrm{ml}$ centrifuge tube and the solution was refrigerated at $4^{\circ} \mathrm{C}$ for $1 \mathrm{~h}$ to precipitate HA. The precipitate was collected by centrifugation at 3,000 $\mathrm{x}$ g for $20 \mathrm{~min}$ and was re-dissolved with a 2 to 3 -fold volume of distilled water. The HA concentration was determined using the carbazole method (Bitter and Muir, 1962) and the optical density was measured at $530 \mathrm{~nm}$. The HA concentration was calculated using a standard curve prepared at different concentrations of HA standards (Sigma-Aldrich, Malaysia). The HA molecular weight $\left(\mathrm{M}_{\mathrm{w}}\right)$ was analyzed by high performance liquid chromatography equipped with a cation-exchange column (Aminex HPX $87 \mathrm{H}$, BioRad Labs, Hercules, CA, USA), a UV detector and the mobile phase was $4 \mathrm{mM} \mathrm{H}_{2} \mathrm{SO}_{4}$ at a steady flow rate $0.5 \mathrm{ml} / \mathrm{min}$.

\section{RESULTS AND DISCUSSION}

\section{Fermentation in Shake-flask}

\section{Effect of Temperature}

The ability of 2 different types of E. coli strains that were cloned with hasA or hasE gene from S. zooepidemicus ATCC 39920 (Samsudin et al., 2011) for HA biosynthesis were investigated. The HA biosynthesis capability of the metabolically engineered $E$. coli strains were investigated in shake-flask culture with different temperature in the presence of IPTG. At three different temperatures investigated $\left(30^{\circ} \mathrm{C}, 37^{\circ} \mathrm{C}\right.$ and $\left.37^{\circ} \mathrm{C}-30^{\circ} \mathrm{C}\right)$, a distinct stationary phase was observed following the exponential phase. As seen from Table 1, the cell production for all strains had very little deviance which was in the range of $\mathrm{OD}_{600}$ between 0.8 to 1.2 . The IPTG inducer was added at $2 \mathrm{~h}$ of fermentation when $\mathrm{OD}_{600}$ reached to about 0.6 and the cell growth was inhibited once IPTG was added and decreased from 1.1 to 0.6 after $12 \mathrm{~h}$ fermentation (data not shown). This indicates that the host strain is susceptible to IPTG (Chien and Lee, 2007a) All the recombinant strains were grown better when the temperature shift from $37^{\circ} \mathrm{C}$ to $30^{\circ} \mathrm{C}$ once the IPTG was added; in contrast, cell growth was the lowest at $37^{\circ} \mathrm{C}$ in comparison to cell grown at $30^{\circ} \mathrm{C}$. The HA biosynthesis is the highest at $37^{\circ} \mathrm{C}$ for all strains, indicating cell lysis at this temperature (data not shown). However, little cell lysis, based on the HA biosynthesis in medium, was observed at $30^{\circ} \mathrm{C}$ and temperature shift from $37^{\circ} \mathrm{C}$ to $30^{\circ} \mathrm{C}$

Cell growth inhibition was observed during HA accumulation. Similar phenomena were observed with all recombinant strains investigated. As can be seen from Table 1, the cell production was similar for sAE and sAE-E cultures. However, the HA production was consistently at least 2-fold and above higher in the strain sAE culture compared to sAE-E cultures. Yu and Stephanopoulos, (2008) deduced that gene coding for phosphoglucoisomerase (pgi, corresponding to hasE in HA synthesis operon) probably plays a critical role to obtain a higher production of HA.

An appreciable amount of HA $(<110 \mathrm{mg} / \mathrm{L})$ was observed for all strains before IPTG induction. The observed HA should result from the expression of HA synthase, due to the optimized medium employed for cell cultivation does contain $50 \mathrm{~g} / \mathrm{L}$ glucose, the HA detected before IPTG induction was probably resulted from the glucose-induced expression of $\mathrm{HA}$ synthase. At $30^{\circ} \mathrm{C}$ fermentation, sAE-E produced $62.7 \mathrm{mg} / \mathrm{L} \mathrm{HA}$, and the highest HA produced is by $\mathrm{sAE}(86.8$ $\mathrm{mg} / \mathrm{L}$ ). On the other hand, the maximum HA biosynthesis was observed when all fermentation run under $37^{\circ} \mathrm{C}$. The sAE yielded about twice the amount of HA $(109.6 \mathrm{mg} / \mathrm{L})$ in shake-flask culture (Table 1). However, for strains sAE-E, the HA biosynthesis was remained low. It is possible that the two plasmids applied were not stable enough for has gene to express. In order to express two heterologous enzymes simultaneously, the energy burden not only slows down the cell growth but also reduces the expression of these two enzymes (Chien and Lee, 2007b). The successful expression of these two heterologous enzymes demonstrates that PRSF vector constructed is effective for protein expression.

Table 1 Effect of temperature on cell growth and HA biosynthesis by different recombinant $E$. coli strains in shake-flask culture after 12 hours of fermentation

\begin{tabular}{lccc}
\hline Temperature & $30^{\circ} \mathrm{C}$ & $37^{\circ} \mathrm{C}$ & $37^{\circ} \mathrm{C}-30^{\circ} \mathrm{C}$ \\
\hline sAE strain & & & \\
$\mathrm{OD}_{600}(\mathrm{~nm})$ & 0.964 & 0.849 & 1.043 \\
HA (mg/L) & 86.8 & 109.6 & 74.8 \\
MW HA (Da) & 11021 & 26802 & 9872 \\
\hline sAE-E strain & & & \\
OD $600(\mathrm{~nm})$ & 0.972 & 0.877 & 0.989 \\
HA (mg/L) & 62.7 & 28.7 & 30.8 \\
MW HA (Da) & 11339 & 27344 & 10145 \\
\hline
\end{tabular}

With co-expression of a heterologous phosphoglucoisomerase (sAE), as consequence, the HA concentration was enhanced from $75.7 \mathrm{mg} / \mathrm{L}$ to 109.6 $\mathrm{mg} / \mathrm{L}$. The results were comparable to sseA and sseAB strains developed by $\mathbf{Y u}$ and Stephanopoulos, (2008) which are 27.8 and $203.5 \mathrm{mg} / \mathrm{L} \mathrm{HA}$, respectively. It is interesting to note that over-expressing of hasA alone does not seem to hinder 
the cell growth and the hasA is not titrating away sugars that are required for cell growth, at least not to dangerously low levels. The over-expression of has caused a significant increase in HA yield and also significantly lowered the molecular weight of HA. The low molecular weight may be clarified by the increased competition for a foxed pool of UDP- monomers leading to suboptimal levels of UDP-Glc UA and UDP-GlcNAc (Chen et al., 2009).

\section{Effect of Inducer on sAE Growth}

The sAE strain was selected to grow on the optimum medium with glucose as a sole carbon source incubated at $37^{\circ} \mathrm{C}$. The growth curve of the sAE strain cultivated in the presence and absence of IPTG (Figure 2) clearly shows that once the inducer IPTG is added, it will cause the cell growth inhibition. In contrast, the cell grew well in without IPTG addition fermentation. The IPTG inducer was added at $2 \mathrm{~h}$ of fermentation when $\mathrm{OD}_{600}$ reached about 0.6. Both growth patterns of cells were same before IPTG is added, the cell growth started to maintain once IPTG is added after $2 \mathrm{~h}$, however, when the fermentation was carried out without induction, the cell growth was still increased exponentially until $10 \mathrm{~h}$. The cell could grow to $1.113 \mathrm{OD}_{600}$ in the absence of IPTG. In contrast, in the presence of IPTG, cell growth was inhibited the cell decreased from 1.113 to $0.748 \mathrm{OD}_{600}$ after $12 \mathrm{~h}$ cultivation. This indicates the strain $\mathrm{sAE}$ is susceptible to IPTG. The advantage of IPTG for in vivo studies is that it cannot be metabolized by $E$. coli, therefore the growth rate of cells (usually maintained with glycerol as the carbon and energy source), is not a variable in the experiment and since cells do not metabolize IPTG, its concentration does no change during the course of an experiment. Besides IPTG, Yu and Stephanopoulos (2008), used $L$-Arabinose as inducer to induce the expression of HAS genes in recombinant $E$. coli. Lactose has been used as a cheap alternative to IPTG to induce lac, but lactose has a much lower induction potential (Kweon et al., 2001) and is consumed whereas IPTG is not consumed.

Although E. coli is a gram-negative bacteria with the cell wall structure composed of lipopolysaccharide, peptidoglycan and lipoprotein, its metabolic pathway for HA synthesis is very similar to that of Streptococcus spp.; the only enzyme of $E$. coli lacks is the hyaluronan synthase. Double expression of has with hasE gene in a single plasmid in the recombinant $E$. coli (sAE) significantly improved the HA biosynthesis from $21.2 \mathrm{mg} / \mathrm{L}$ at $10 \mathrm{~h}$ (without IPTG induction) to $110.5 \mathrm{mg} / \mathrm{L}$ (with IPTG induction) at $4 \mathrm{~h}$ of fermentation in shake-flask culture. This indicated that the IPTG as an inducer is required to induce has A and hasE genes. This result was significantly higher than $\mathbf{Y u}$ and Stephanopoulos, (2008) who only managed to produce $95.9 \mathrm{mg} / \mathrm{L} \mathrm{HA}$ by using triple expression sp ABC recombinant $E$. coli strain.

The hyaluronan synthase enzyme involved in HA synthesis in Streptococcus and mammals has shown to prefer magnesium ions while Chorella virus HAS prefers manganese ions to stimulate the synthesis HA (Yamada and Kawasaki, 2005). The use of magnesium sulphate in HA biosynthesis likewise, has been preferred by recombinant $E$. coli. Large number of ATP molecules are consumed in various enzymatic reactions involved in HA biosynthesis pathway, hence source of phosphate is essential to synthesize ATPs. In this study, sal dipotassium hydrogen and potassium dihygrogen phosphate used as a source of inorganic phosphate in recombinant $E$. coli fermentation.

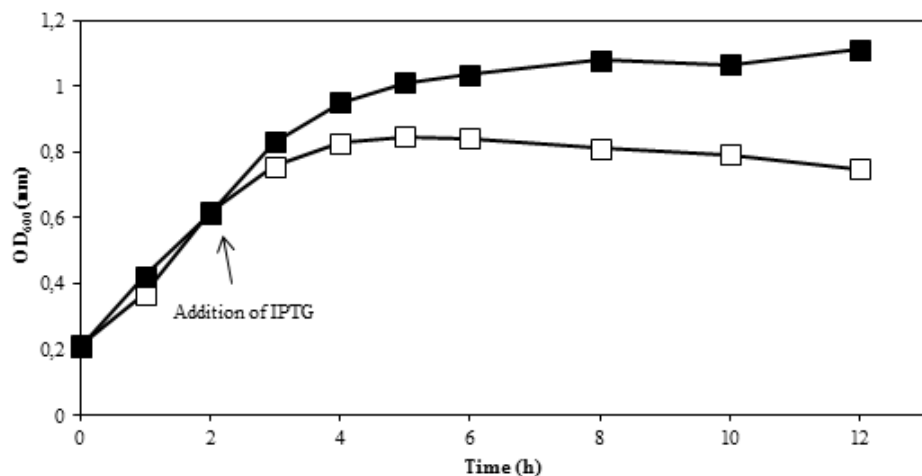

Figure 2 The growth curves of sAE strain cultivated in the shake-flask culture with the presence and absence of IPTG incubated at $37^{\circ} \mathrm{C}$. (घ) - without IPTG addition ; ( $\square$ ) - with IPTG addition

\section{Effect of IPTG Induction Time on sAE Growth}

In order to determine the time course of induction, two shake-flask cultures experiments were performed. The first culture was grown at $37{ }^{\circ} \mathrm{C}$ until the sAE growth, $\mathrm{OD}_{600}$ reached 0.6 and then $0.5 \mathrm{mM}$ IPTG was added to the medium. The same amount of IPTG was also added to the second culture experiment when its $\mathrm{OD}_{600}$ reached 1.0. After the addition of IPTG to the cultures, the incubation was continued and samples were taken every hour to determine the cell growth, glucose consumption and HA concentration. As a result, the growth curve is shown in Figure 3. The cell growth was higher $\left(\mathrm{OD}_{600}\right.$ is 1.088$)$ with the addition of $0.5 \mathrm{mM}$ IPTG at $\mathrm{OD}=1.0$ if compared to $\mathrm{OD}=0.6$. The maximum of HA biosynthesis was found to be attained $4 \mathrm{~h}$ after the addition of IPTG to the medium, which is $115.4 \mathrm{mg} / \mathrm{L}(\mathrm{OD}=0.6)$ and $90.8 \mathrm{mg} / \mathrm{L}(\mathrm{OD}=1.0)$. The induction times are considered to be important parameters in the production of the recombinant strains and they need to be carefully optimized to increase the yield of the product. The addition of IPTG in the middle of exponential phase able to achieve the higher HA production compared to addition of IPTG at late exponential phase. The strain starts goes into the stationary phase. Induction in the stationary phase reduces culture viability and can lead to production of proteases that can breakdown the desired recombinant protein (Corchero et al. 2001). On the other hand, if induction too early can slow down the doubling time of bacterial cells. The timing of induction of new recombinants need to be empirically determined for each new clone, due to the cellular responses depend on a number of interacting factors including the host/vector system (CserjanPuschmann et al., 1999).
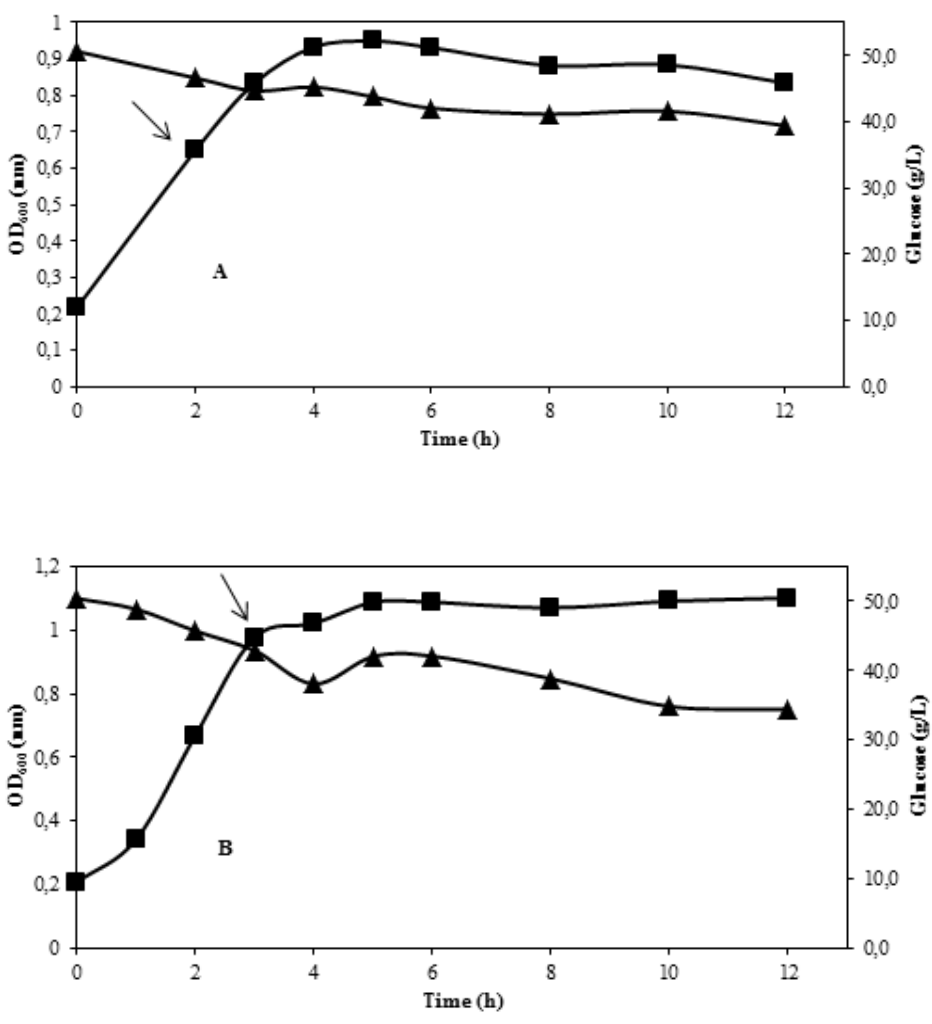

Figure 3 The growth curves of the strain sAE cultivated in the presence of IPTG with different induction time. The arrow indicated that IPTG is added. (A) IPTG added when $\mathrm{OD}_{600}$ is 0.6 ; (B) IPTG added when $\mathrm{OD}_{600}$ is 1.0

\section{Effect of IPTG Concentration on HA biosynthesis by SAE}

In order to determine the effect of different concentrations of IPTG on HA biosynthesis, addition of $0.1,0.5$ and $1 \mathrm{mM}$ IPTG were examined. All cultures of strain sAE were grown until the $\mathrm{OD}_{600}$ reached 0.6 in the middle of exponential phase, $0.1,0.5$ and $1 \mathrm{mM}$ IPTG was added to each culture flask respectively, and incubated till 12 hours. A control experiment was also performed in which the addition of IPTG was omitted. From Table 2, it can be seen that in the control experiment, the cells also grew well, however there is no HA production. The IPTG induction resulted in growth of sAE and HA production. An increment of IPTG concentration has meaningful effect on cell and HA production.

From Table 2, the cell growth was higher with no IPTG addition compared to 0.1 $\mathrm{mM}$ of IPTG addition (OD $=1.113$ and 1.1 , respectively). The cell growth was reduced when the IPTG concentration was increased from 0.1 to $0.5(\mathrm{OD}=0.949)$ and $1.0 \mathrm{mM}(\mathrm{OD}=0.849)$. On the other hand, the HA concentration was the highest when the cell growth was at the lowest when $1 \mathrm{mM}$ IPTG was added This result proved the statement of there is a stiff competition for metabolites between HA production and cellular growth (Mao et al., 2009). From the Table $\mathbf{2}$, the HA concentration obtained are comparable, however, there is a significant difference when we compare the molecular weight of HA measured after the fermentations. Although HA with a relatively low molecular weight is broadly used in cosmetics fields, high molecular weight HA is more appealing to be used in medical applications (Liu et al., 2008). High molecular weight HA is also highly viscous which makes it ideal for some uses such as reducing the adhesion formation of post-surgery (Takeda et al. 2011). The highest HA molecular weight can be achieved at 40928 Dalton using $1 \mathrm{mM}$ of IPTG, which is about 3 folds higher than other IPTG concentration. At a concentration of $1 \mathrm{mM}$ the lac promoter appeared to be fully induced. The concentration of IPTG (between 0.1 
$\mathrm{mM}$ and $2 \mathrm{mM}$ ) required for complete induction is known to vary widely with clones (Li et al., 1999; Madurawe et al., 2000). The presence of excessive IPTG reduced the final cell density. These results concur with Yee and Blance (1993) who observed a reduced growth rate in $E$. coli when IPTG concentration exceeds $1 \mathrm{mM}$.

Table 2 Effect of IPTG concentration on maximum cell growth, HA biosynthesis and molecular weight by strain sAE using shake-flask culture

\begin{tabular}{cccc}
\hline IPTG $(\mathbf{m M})$ & OD $_{\mathbf{6 0 0}}(\mathbf{n m})$ & HA $(\mathbf{m g} / \mathbf{L})$ & MW HA (Da) \\
\hline 0 & 1.113 & 0 & 0 \\
0.1 & 1.1 & 99.6 & 14263 \\
0.5 & 0.949 & 103.5 & 14641 \\
1 & 0.849 & 109.6 & 40928 \\
\hline
\end{tabular}

\section{Fermentation in 2 L Stirred Tank Bioreactor}

\section{Batch Cultivation}

Batch bioreactor studies were conducted with both the recombinant strains (sAE and sAE-E) initially with controlled DO at $20 \%$. With both recombinant strains, it was observed that glucose was only consumed 8 to $9 \mathrm{~g} / \mathrm{L}$ throughout the $10 \mathrm{~h}$ fermentation (as shown at Table 3). Cell using glucose as carbon source can theoretically be thought of as used for four different purposes in recombinant protein producing cells, i.e. for: growth, maintenance, respiration and product formation. If the concentration is very high glucose will further be used for formation of overflow metabolite formation. Accumulation of acetate is a common obstacle to achieving high levels of recombinant protein and other fermentation products in E. coli (Chen and Bailey, 1993). With excess glucose in the medium, E. coli cells tend to synthesize high levels of acetate and other organic acids, such as lactic acid, usually resulting in cell growth inhibition and reduced HA production due to the reduced $\mathrm{pH}$ of the medium (Liu et al., 2011). The growth curve of recombinant $E$. coli strains is shown in Figure 4. The cell growth curve in $\mathrm{SAE}$ and sAE-E cultures are same, the maximum $\mathrm{OD}_{600}$ in strain $\mathrm{SAE}$ is 1.022 , and 1.075 for strain sAE-E cultures. On the other hand, strain sAE produced maximum of $50.7 \mathrm{mg} / \mathrm{L}$ of $\mathrm{HA}$, while strain sAE-E produced nearly 5 times lower HA, which is only $10.3 \mathrm{mg} / \mathrm{L}$. Since HA production increased approximately 2.5 fold over the non-aerated condition (Prasad et al., 2010), HA production also further improved by controlled DO from $20 \%$ to $30 \%$ and to 50 $\%$.

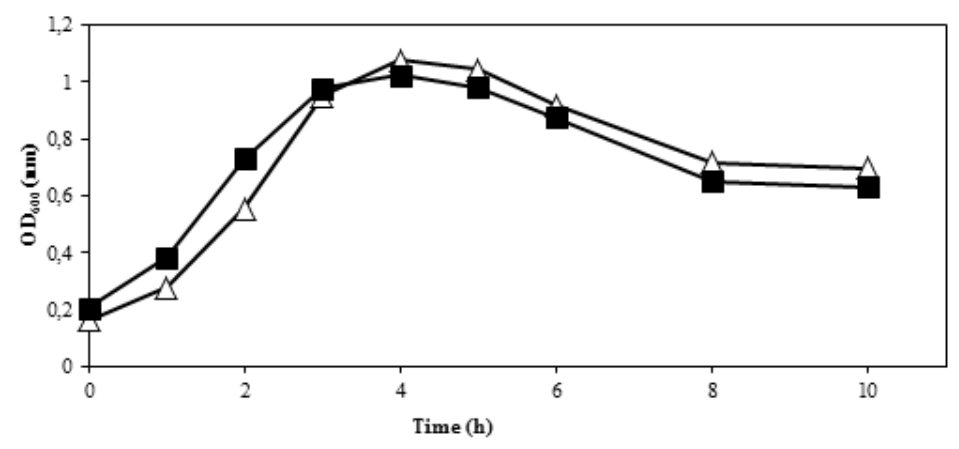

Figure 4 Growth curves of strains sAE and sAE-E in batch cultivation using $2 \mathrm{~L}$ of stirred tank bioreactor. ( $\square)$ - strain sAE; $(\Delta)$ - strain sAE-E

The operation conditions of the process greatly affect the metabolic behavior of the production strain. The genetic manipulation themselves are not enough to make a strain achieve maximum theoretical yield. HA synthesis is a demanding process, requiring large amounts of energy. Four molecules ATP are needed for a single molecule of disaccharide repeating unit. Aerobic fermentation is therefore favorable to HA biosynthesis. A common challenge in metabolic engineering is to ensure adequate supply of precursors for target molecules. This is particularly challenging since HA synthesis tightly couples with the cell growth Consequently, cell growth inevitably competes with the HA synthesis for the same precursor molecules. The ability to decouple these two processes will not only increase the efficiency of the processes but also allow synthesis process to be controlled independent of cell growth such that any conditions limiting cell growth may not affect the synthesis (Mao et al., 2009).

Table 3 shows the cell and HA production with different DO levels, while the impeller speed control remained the same along with the standard fermentation conditions mentioned above. Under aerobic conditions, the final cell growth are not affected by various DO levels, indicating that cell growth is unaffected by presence of oxygen, regardless the DO levels. However, HA synthesis is affected by different DO levels. The highest HA synthesis attained when the DO is controlled at $30 \%$ which is $127 \mathrm{mg} / \mathrm{L}$. This result can be supported by Huang et al. (2006) found that DO played an important role as a stimulant in HA synthesis and there existed a critical DO level of $5 \%$ during HA fermentation, meaning the capacity of HA synthesis was affected below this level. Furthermore, the yield coefficient $\mathrm{Y}_{\mathrm{p} / \mathrm{x}}$ was investigated, and the results are summarized in Table 3 There were no distinct differences in the values of $\mathrm{Y}_{\mathrm{p} / \mathrm{x}}$ under $30 \%$ and $50 \%$, indicating that the efficiency of the HA synthesis was unaffected when DO level is higher than $30 \%$. However, if compared to DO at $20 \%$, the $\mathrm{Y}_{\mathrm{p} / \mathrm{x}}$ is about two fold lower than DO above $30 \%$. The highest concentration of the inclusion body protein and the volumetric titres of Eg95 were attained at $30 \%$ DO level (Manderson et al., 2006). Chisti and Moo Young (1996) stated that maintaining a high dissolved oxygen level in high cell density cultures requires intense agitation and aeration that can damage fragile recombinant cells.

From our results, it shown that HA biosynthesis in bioreactor under controlled $\mathrm{pH}$ conditions results in better glucose uptake and enhances the productivity of culture in comparison to shake-flask cultures. It is possible that the development of acid tolerance response (Sriraman and Jayaraman, 2006) in the shake-flask cultures due to acidification of the broth limits the energy and precursor availability for HA biosynthesis.

Molecular weight is one of key characteristic of HA product. Chen et al. (2009) have shown that in S. zooepidemicus, the overexpression of single genes involved in the UDP-glucuronic acid biosynthesis pathway decreased the HA molecular weight, whereas the overexpression of single genes involved in the UDP-N acetylglucosamine biosynthesis pathway increased the HA molecular weight. In this study, the HA molecular weight was found to be sensitive to the DO level, and the results are shown in Table 3. At DO is $20 \%$, the HA molecular weight was only $54166 \mathrm{Da}$, yet it reached $70056 \mathrm{Da}$ at a DO level of $30 \%$, and then decreased to $55041 \mathrm{Da}$ at $50 \%$. This phenomenon was caused by the balance between HA synthesis (Armstrong and Johns, 1997) and oxygen-mediated degradation with various DO levels. As such, the HA molecular weight increased owing to the effect of the DO on the HA synthesis, and then decreased because of oxygen radical degradation. Thus, the HA molecular weight at $50 \%$ DO was less than that at $30 \%$ DO owing to oxygen radical degradation.

Cleary and Larkin, (1979) previously proposed a defense mechanism where HA capsules protect cells from oxygen in Group A, and the protective mechanism is activated in the presence of oxygen. In other words, an appropriate DO level could stimulate the synthesis of HA, and when DO level was higher than the critical level of $30 \%$, the stimulation effect was not so significant. Therefore developing an efficient DO control approach was very important to improve HA productivity. However, there are no reports regarding the influence of DO control approach on the microbial HA production by recombinant $E$. coli.

Table 3 Comparison of kinetic parameters values HA biosynthesis at different controlled DO levels in a $2 \mathrm{~L}$ stirred tank bioreactor using strain sAE

\begin{tabular}{lccc}
\hline Kinetic parameter values & $20 \%$ & $30 \%$ & $50 \%$ \\
\hline $\mathrm{t}(\mathrm{h})$ & 12 & 8 & 8 \\
$\mathrm{OD}_{600}(\mathrm{~nm})$ & 0.815 & 0.794 & 0.758 \\
$\mathrm{P}_{\mathrm{m}}(\mathrm{g} / \mathrm{L})$ & 0.057 & 0.127 & 0.118 \\
$\mathrm{~S}_{0}-\mathrm{S}_{\mathrm{i}}(\mathrm{g} / \mathrm{L})$ & 8.152 & 8.999 & 9.099 \\
$\mathrm{Y}_{\mathrm{OD} / \mathrm{s}}(\mathrm{OD} / \mathrm{g})$ & 0.100 & 0.088 & 0.083 \\
$\mathrm{Y}_{\mathrm{p} / \mathrm{s}}(\mathrm{g} / \mathrm{g})$ & 0.007 & 0.014 & 0.013 \\
$\mathrm{Y}_{\mathrm{p} / \mathrm{OD}}(\mathrm{g} / \mathrm{OD})$ & 0.070 & 0.160 & 0.155 \\
$\mathrm{P}_{\mathrm{r}}(\mathrm{g} / \mathrm{L} / \mathrm{h})$ & 0.005 & 0.016 & 0.015 \\
$\mathrm{MW}(\mathrm{Da})$ & 54166 & 70056 & 55041 \\
\hline
\end{tabular}

\section{Fed-batch cultivation}

Since HA biosynthesis of recombinant $E$. coli in our research is in simple batch culture in flask or bioreactor, it is reasonable that they are not very high Therefore, we proceed to fed-batch cultivation by using sAE strain. In order to investigate the potential of the recombinant strain for industrial application and to probe possible limitation for HA synthesis in recombinant strains, a fed-batch fermentation process was developed. Fermentation processes of E. coli are commonly operated in fed-batch mode in order to prevent the accumulation of toxic substrates or products (Lee et al., 1999), thus allowing the achievement of higher product concentrations. The bacteria $E$. coli is usually grown under this kind of operation due to the well-known negative effect of acetate, which is produced when the substrate, glucose, is presented above certain concentrations (van de Walle and Shiloach, 1998).

In the constant feeding rate fed-batch cultivation, $10 \mathrm{~g} / \mathrm{L}$ of glucose was fed into the bioreactor at a constant feeding rate of $2 \mathrm{ml} / \mathrm{min}$. The cell reached $\mathrm{OD}_{600}$ at 1.923, however the HA biosynthesis in the constant feeding rate fed-batch cultivation is only $40 \mathrm{mg} / \mathrm{L}, 31 \%$ lower than batch cultivation. The comparison of batch and constant feeding rate fed-batch on HA production was provided in Table 4. Batch culture evidently showed the highest HA productivity on glucose and fed-batch culture had a higher cell yield $\left(\mathrm{Y}_{\mathrm{OD} / \mathrm{s}}\right)$ on glucose. The average specific HA synthesis rate in fed-batch culture was 0.004 (g HA/OD/h) compared with $0.016(\mathrm{~g} \mathrm{HA} / \mathrm{OD} / \mathrm{h})$ in batch culture. Therefore, it can be deduced that fed- 
batch culture was more favorable for cell growth compared to batch culture which was a more favorable way for the synthesis of HA. Fed-batch culture was chosen because of the desire to probe limitation under more practically useful conditions which lead to high titers in HA (Mao et al., 2009). The concentration of acetic acid was increased to $1.623 \mathrm{~g} / \mathrm{L}$ compared with $1.407 \mathrm{~g} / \mathrm{L}$ in batch culture. The average specific HA synthesis rate in fed-batch culture was $0.021(\mathrm{~g}$ $\mathrm{HA} / \mathrm{OD} / \mathrm{h})$ compared with 0.16 (g HA/OD/h) in batch culture. The synthesis of acetic acid was coupled to cell growth, and thus the fed-batch culture evidenced a higher acetic acid yield as compared with that in the batch culture. In comparison of HA molecular weight in fed-batch cultivation $(60881 \mathrm{Da})$ is $10 \%$ lower than batch cultivation $(70556 \mathrm{Da})$. In the fed-batch cultivation, the increased accumulation of acetic acid inhibited HA biosynthesis more severely, thus resulting in a reduced production and productivity of HA.

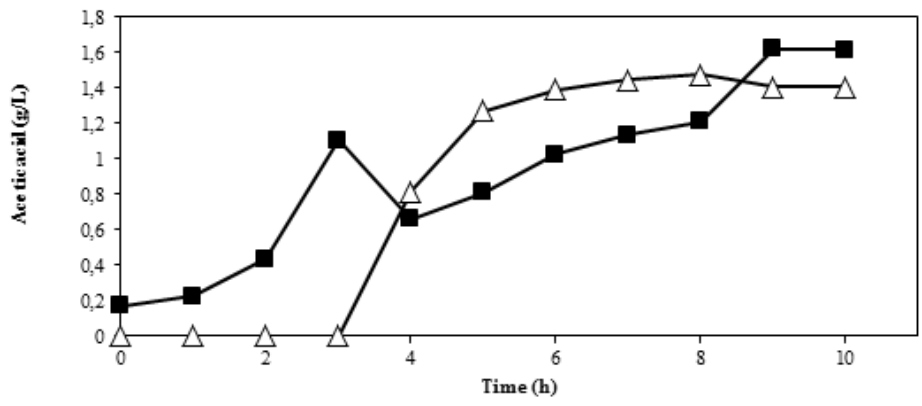

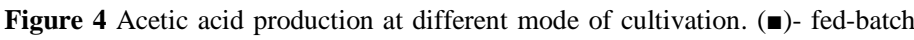
cultivation $(\Delta)$ - batch cultivation

The high cell growth in fed-batch cultivation resulted from the low inhibition of glucose in the cells. However it appeared that low glucose concentrations were not favorable for the synthesis of HA. It was previously reported that there was competition between HA synthesis and cell growth for the common precursors UDP-glucuronic acid and UDP-N-Acetyl Glucosamine. It should be noted that cell wall is necessary for cell growth, while HA as a cell capsule is not a necessary component for cell growth. Carbon source was utilized preferably for cell growth and thus HA synthesis is inhibited, especially at low substrate concentration in fed-batch culture (Chong et al., 2005). Therefore, a lower HA productivity in fed-batch culture compared to batch culture was observed in the present study. The competition between cell growth and HA synthesis was also observed by other researchers (Chong et al., 2005). Hence, the lower HA productivity in fed-batch culture resulted from the competition between cell growth and HA synthesis, not the decreased HA synthesis ability of $S$ zooepidemicus.

Other metabolites in the HA biosynthetic pathways such as glucose-6-phosphate and fructose-6-phosohate are consumed in the pentose phosphate pathway an glycolysis, respectively. Thus, there is stiff competition for the metabolites between HA production and cellular growth, and there is a close correlation between energy metabolism and precursor supply. As discussed above, fed-batch culture was favorable for cell growth, and cells in fed-batch culture can reach a concentration as high as that in batch culture but in a shorter time.

Table 4 Comparison of kinetic parameter values of batch and constant feeding rate fed-batch cultivation on HA biosynthesis by sAE strain

\begin{tabular}{lcc}
\hline & Batch Fermentation & Fed-batch Fermentation \\
\hline $\mathrm{t}(\mathrm{h})$ & 8 & 9 \\
$\mathrm{OD}_{600}(\mathrm{~nm})$ & 0.794 & 1.923 \\
$\mathrm{P}_{\mathrm{m}}(\mathrm{g} / \mathrm{L})$ & 0.127 & 0.040 \\
$\mathrm{AA}_{\mathrm{m}}(\mathrm{g} / \mathrm{L})$ & 1.407 & 1.623 \\
$\mathrm{Y}_{\mathrm{OD} / \mathrm{s}}(\mathrm{OD} / \mathrm{g})$ & 0.088 & 0.134 \\
$\mathrm{Y}_{\mathrm{p} / \mathrm{OD}}(\mathrm{g} / \mathrm{OD})$ & 0.160 & 0.021 \\
$\mathrm{P}_{\mathrm{r}}(\mathrm{g} / \mathrm{L} / \mathrm{h})$ & 0.016 & 0.004 \\
$\mathrm{MW}(\mathrm{Da})$ & 70056 & 60881 \\
\hline
\end{tabular}

\section{CONCLUSION}

In this study, the hasA and hasE genes expressed together in a plasmid in recombinant $E$. coli strains were successfully produced HA using glucose as a carbon source under aerobic condition. Production of $127 \mathrm{mg} / \mathrm{L} \mathrm{HA}$ was observed in a batch fermentation process with the highest HA molecular weight (70056 Da) using strain sAE in $2 \mathrm{~L}$ stirred tank bioreactor with controlled DO a $30 \%$. The fed-batch culture with constant feeding of glucose was favorable for cell growth and the highest $\mathrm{OD}_{600}$ achieved at 1.923. However, the HA biosynthesis and molecular weight in fed-batch culture were lower than that observed in the batch culture. Further optimization of fermentation process and control strategies should lead to an even higher yield.

\section{REFERENCES}

Armstrong, D. C. \& Johns, M. R. (1997). Culture conditions affect the molecular weight properties of hyaluronic acid produced by Streptococcus zooepidemicus Applied and Environmental Microbiology, 63(7), 2759- 2764.

Bitter, T. \& Muir, H. M. (1962). A modified uronic acid carbazole reaction, Analytical Biochemistry, 4, 330-333. http:// http://dx.doi.org/10.1016/0003 2697(62)90095-7

Chen, R. \& Bailey, J. E. (1993). Observations of aerobic, growing Escherichia coli metabolism using an on-line nuclear magnetic resonance spectroscopy system. Biotechnology and Bioengineering, 42(2), 215-221. http://dx.doi.org/10.1002/bit.260420209

Chen, S.J., Chen, J.L., Huang, W.C. \& Chen, H.L. (2009). Fermentation process development for hyaluronic acid production by Streptococcus zooepidemicus ATCC 39920. Korean Journal of Chemical Engineering, 26 (2), 428-432 http://dx.doi.org/10.1007/s11814-009-0072-3

Chien, LJ, \& Lee, C.K. (2007a). Enhanced hyaluronic acid production in Bacillus subtilis by coexpressing bacterial haemoglobin. Biotechnology Progress, 23(5), 1017-1022. http://dx.doi.org/10.1021/bp070036w

Chien, L.J. \& Lee, C.K. (2007b). Hyaluronic acid production by recombinant Lactococcus lactis. Applied Microbiology and Biotechnology, 77(2), 339-346. http://dx.doi.org/10.1007/s00253-007-1153-z

Chisti, Y. \& Moo-Young, M. (1996). Bioprocess intensification through bioreactor engineering. Chemical Engineering Research and Design, 74(5), 575 583.

Chong, B.F., Blank, L.M., Mclaughlin, R. \& Nielsen, L.K. (2005). Microbia hyaluronic acid production. Applied Microbiology and Biotechnology, 66( 4), 341-351. http://dx.doi.org/10.1007/s00253-004-1774-4

Cleary, P.P. \& Larkin, A. (1979). Hyaluronic acid capsule: Strategy for oxygen resistance in group A streptococci. Journal of Bacteriology, 140(3), 1090-1097.

Corchero, J. L., Cubarsi, R., Villa, P., Aris, A. \& Villaverde, A. (2001). Cell lysis in Escherichia coli cultures stimulates growth and biosynthesis of recombinant proteins in surviving cells. Microbiological Research, 156(1), 13-18 http://dx.doi.org/10.1078/0944-5013-00066

Cserjan-Puschman, M., Kramer, W., Duerrschmid, E., Striedner, G. \& Bayer,K (1999). Metabolic approaches for the optimization of recombinant fermentation processes. Applied Microbiology and Biotechnology, 53(1), 43-50. http://dx.doi.org/10.1007/s002530051612

DeAngelis,P. L., Papaconsttantinou, J. \& Weigel, P.H. (1993). Molecular cloning, identification, and sequence of the hyaluronan synthase gene from group A Streptococcus pyogenes. Journal of Biological Chemistry, 268, 19181-19184.

Frohberg, C. \& Koch, R. (2004). Methods and means for the manufacture of hyaluronan, U.S. Provisional Application No. 60612344, and European Application No.04090373.

Huang, W. C., Chen, S.J. \& Chen, T.L. (2006). The role of dissolved oxygen and function of agitation in hyaluronic acid fermentation. Biochemical Engineering Journal, 32(3), 239-243. http://dx.doi.org/10.1016/j.bej.2006.10.011

Jongsareejit, B., Bhumiratana, A., Morikawa, M. \& Kanaya, S. (2007). Cloning of hyaluronan synthase (sz-has) gene from Streptococcus zooepidemicus in Escherichia coli. Science Asia Journals, 33, 389-395. http://dx.doi.org/10.2306/scienceasia1513-1874.2007.33.389

Kogan, G., Solte's, L., Stern, R. \& Germeiner, P. (2007). Hyaluronic acid: A natural biopolymer with a broad range of biomedical and industrial application Biotechnology Letters, 29(1), 17-25. http://dx.doi.org/10.1007/s10529-006-9219-

Kweon, D. H., Han, N. S., Park, K. M. \& Seo, J. H. (2001). Overproduction of Phytolacca insularis protein in batch and fed-batch culture of recombinan Escherichia coli. Process Biochemistry, 36(6), 537-542. http://dx.doi.org/10.1016/s0032-9592(00)00237-5

Lee, J., Lee, S. Y., Park,S \& Middelberg, A.P.J. (1999). Control of fed-batch fermentations. Biotechnology Advances, 17(1), 29-48 http://dx.doi.org/10.1016/s0734-9750(98)00015-9

Li, N., Qu, L-J., Liu, Y., Li, Q., Gu, H. \& Chen, Z. (1999). The refolding, purification, and activity analysis of a rice Bowman-Birk iinhibitor expresses in Escherichia coli. Protein Expression and Purification. 15(1), 99-104. http://dx.doi.org/10.1006/prep.1998.0989

Liu, L., Du, G. C., Chen, J., Wang, M. \& Sun, J. (2008). Enhanced hyaluronic acid production by a two-stage culture strategy based on the modelling of batch and fed batch cultivation of Streptococcus zooepidemicus. Bioresource Technology, 99(17), 8532-8536. http://dx.doi.org/10.1016/j.biortech.2008.02.035 Liu, L., Liu, Y., Li, J., Du, G., \&Chen, J. (2011). Microbial production of hyaluronic acid: current state, challenges, and perspectives. Microbial Cell Factories, 10 ( 99), 1-9. http://dx.doi.org/10.1186/1475-2859-10-99

Liu, L., Wang, M., Du, G.C. \& Chen, J. (2009). Microbial production of low molecular weight hyaluronic acid by adding hydrogen peroxide andvascorbate in batch culture of Streptococcus zooepidemicus. Bioresource Technology, 100(1) 362-367. http://dx.doi.org/10.1016/j.biortech.2008.05.040 
Madurawe, R. D., Chase, T.E., Tsao, E. I. \& Bently, W.E. (2000). A recombinant lipoprotein antigen against Lyme disease expressed in E.coli: Fermentor operating strategies for improved yield. Biotechnology Progress, 16(4), 571-576. http://dx.doi.org/10.1021/bp0000555

Manderson, D., Dempster, R. \& Chisti, Y. (2006). A recombinant vaccine against hydatidosis: Production of the antigen in Escherichia coli. Journal of Industrial Microbiology and $\quad$ Biotechnology, 33(3), 173-182. http://dx.doi.org/10.1007/s10295-005-0046-3

Mao, Z., Shin, H. \& Chen, R. (2009). A recombinant E. coli bioprocess for hyaluronan synthesis. Applied Microbiology and Biotechnology, 84(1), 63-69. http://dx.doi.org/10.1007/s00253-009-1963-2

Prasad, S. B., Jayaraman, G. \& Ramachandran, K. B. (2010). Hyaluronic acid production is enhanced by the additional co-expression of UDP-glucose pyrophosphorylase in Lactococcus lactis. Applied Microbiology and Biotechnology, 86(1), 273-283. http://dx.doi.org/10.1007/s00253-009-2293-0

Rehm, B. (2009). Microbial production of biopolymers and polymer precursors: applications and perspectives, Horizon Scientific Press, New Zealand.

Samsudin, M. A. Ariff, A., Rosfarizan, M \& Raha, A.R. (2011). Cloning and expression of hyaluronan synthase (has A) gene in Escherichia coli. International Congress of Malaysian Society for Microbiology, Penang, Malaysia.

Shih, W.Y., Lai, H.H., Chen, N.Y., Shih, I.L., Huang, Y.C., Lin, T.S. \& Wu, J.Y. (2013). Effect of environmental factor on production of hyaluronic acid by Streptococcus zooepidemicus. International Journal of Science and Engineering, 3 (4), 5-21. http://dx.doi.org/10.6159/IJSE.2013.(3-4).02

Sriraman, K. \& Jayaraman, G. (2006). Enhancement of recombinant streptokinase production in Lactococcus lactis by suppression of acid tolerance response. Applied Microbiology and Biotechnology, 72(6), 1202-1209. http://dx.doi.org/10.1007/s00253-006-0410-x

Takeda, K., Sakai, N., Shiba, H., Nagahara, T., Fujita, T., Kajiya, M., Iwata, T., Matsuda, S., Kawahara, K., Kawaguchi, H. \& Kurihara, H. (2011) Characteristics of high-molecular-weight hyaluronic acid as a brain-derived neurotrophic factor scaffold in periodontal tissue regeneration. Tissue

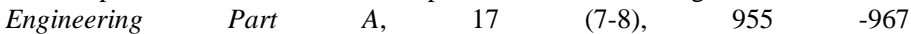
http://dx.doi.org/10.1089/ten.tea.2010.0070

Van de Walle, M. \& Shiloach, J. (1998). Proposed mechanisms of acetate accumulation in two recombinant Escherichia coli strains during high density fermentation. Biotechnology and Bioengineering, 57(1), 71-78 http://dx.doi.org/10.1002/(sici)1097-0290(19980105)57:1<71::aid-bit9>3.0.co;2$\underline{s}$

Widner, B., Behr, R., Von Dollen, S., Tanf, M., Heu, T., Sloma, A., Sternberg, D., DeAngelis, P. L., Weigel, P. H. \& Brown, S. (2005). Hyaluronic acid production in Bacillus subtilis. Applied Environment and Microbiology, 71(7), 3747-3752. http://dx.doi.org/10.1128/aem.71.7.3747-3752.2005

Yamada, T. \& Kawasaki, T. (2005). Microbial synthesis of hyaluronan and chitin: new approaches. Journal of Bioscience and Bioengineering, 99(6), 521528. http://dx.doi.org/10.1263/jbb.99.521

Yee, L. \& Blanch, H. W. (1993). Recombinant trypsin production in high cell density fed-batch cultures of Escherichia coli. Biotechnology and Bioengineering, 41(8), 781-790. http://dx.doi.org/10.1002/bit.260410804

Yu, H. \& Stephanopoulos G. (2008). Metabolic engineering of Escherichia coli for biosynthesis of hyaluronic acid. Metabolic Engineering, 10(1), 24-32. http://dx.doi.org/10.1016/j.ymben.2007.09.001 